Frontiers of Information Technology \& Electronic Engineering www.jzus.zju.edu.cn; engineering.cae.cn; www.springerlink.com ISSN 2095-9184 (print); ISSN 2095-9230 (online)

E-mail: jzus@zju.edu.cn

\title{
Erratum:
}

\section{Erratum to: ONFS: a hierarchical hybrid file system based on memory, SSD, and HDD for high performance computers}

\author{
Xin $\mathrm{LIU}^{\$ 1,2}$, Yu-tong $\mathrm{LU}^{1}$, Jie $\mathrm{YU}^{3}$, Peng-fei WANG ${ }^{3}$, Jie-ting $\mathrm{WU}^{2}$, Ying $\mathrm{LU}^{2}$ \\ ${ }^{1}$ School of Computer, National University of Defense Technology, Changsha 410073, China \\ ${ }^{2}$ Computer Science and Engineering, University of Nebraska-Lincoln, Lincoln 68588, USA \\ ${ }^{3}$ National Supercomputing Center, Tianjin 300457, China \\ E-mail: xliu@cse.unl.edu; ytlu@nudt.edu.cn; \{yujie,wangpf\}@nscc-tj.gov.cn; \{jwu, ylu\}@cse.unl.edu
}

https://doi.org/10.1631/FITEE.17e0626

Erratum to: Front Inform Technol Electron Eng, 2017 18(12):1940-1971 https://doi.org/10.1631/FITEE.1700626

In the original version of this article, the abbreviation 'OWDM' was incorrectly defined. The phrase 'orthogonal wavelength division multiplexing' should all be changed to 'one-way wave depth migration'. 